\title{
PROJETOS PEDAgógICOS E POLÍTICAS PÚBLICAS PARA A EDUCAÇÃO INFANTIL NO MUNICÍPIO DE PIRAQUARA - PARANÁ (1993-2004)
}

\author{
Danielle Marafon $^{1}$ \\ Universidade Estadual do Paraná- UNESPAR
}

\section{RESUMO}

Este artigo visa discutir as políticas públicas estabelecidas para a Educação Infantil, no Município de Piraquara, no Estado do Paraná, no período circunscrito entre 1993 e 2004, no qual duas propostas curriculares (Projeto Araucária 1993-2000) e (Proposta Curricular da Educação Infantil 2001-2004), foram orientadoras das ações pedagógicas junto às crianças de 0 a 6 anos. Discorre sobre a natureza das políticas públicas, sem esquecer a história da Educação Infantil no Brasil e na Europa como pano de fundo para o processo de organização da Educação Infantil no Município de Piraquara, enfatizando o sentido de problematizar as legislações educativas a fim de evidenciar a relação entre os fundamentos legais e as políticas públicas para a educação, bem como as implicações das políticas públicas no processo de ensino-aprendizagem da criança pequena. Apoia-se nos conceitos históricos, na produção historiográfica da Educação Infantil e nos documentos (Projeto Araucária e Proposta Curricular da Educação Infantil), os quais nos possibilitam debater sobre as acepções de infância, de Educação Infantil, de métodos de ensino-aprendizagem, de formação de professor e de concepções de gestão que emergiram das duas propostas pedagógicas elaboradas naquele período.

Palavras-chave: Infância; Educação Infantil; proposta pedagógica; políticas públicas.

\section{PEDAGOGIC PROJECTS AND STATE POLICIES FOR CHILDREN'S EDUCATION IN THE MUNICIPALITY OF PIRAQUARA - PARANA (1993-2004)}

\begin{abstract}
The aim of this article is to discuss the state policies established for Children's Education in the municipality of Piraquara in the State of Paraná, between 1993 and 2004 in which two curriculum proposals (Araucaria Project 1993-2000 and Curriculum Proposal for Children's Education 2001-2004) guided the pedagogical actions with children from 0 to 6 years of age. The article also discourses on the nature of state policies without overlooking the history of children's education in Brazil and in Europe as the background in the process of organizing Children's Education in the Municipality of Piraquara, emphasizing the importance of questioning the educational legislation in order to highlight the relationship between the legal bases and state policies for education, as well as the implications of state policies in the process of teaching and learning for small children. The article bases itself on the historical concepts, on the historiographic productions of children's education and on documents (Araucaria Project and Curriculum Proposal for Children's Education), which enable us to debate on the meaning of childhood, on children's education, on the teaching and learning methods, on teacher training and on the conceptions regarding administration which emerged from the two proposals developed during that period. Keywords: Childhood; children's education; pedagogic proposal; state policies.
\end{abstract}




\section{Introdução}

O objetivo deste texto é discutir a organização pedagógica da Educação Infantil no Município de Piraquara, enfatizando uma abordagem do Projeto Araucária (1993) e da Proposta Pedagógica da Secretaria Municipal da Educação (2004). Piraquara é um dos municípios que compõem a grande Curitiba. De todos os municípios da região metropolitana é um dos que vem apresentando o maior índice de crescimento populacional. Além disso, tem um baixo índice de desenvolvimento humano. É possível afirmar que se trata de uma cidade-dormitório, pois no município a oferta de trabalho é baixíssima, sendo uma das razões o fato de a cidade ser impedida de trazer indústrias poluentes, pois ela abriga grande área de preservação ambiental e é chamada de capital das águas, abastecendo mais de $50 \%$ da água consumida em Curitiba e demais cidades da região metropolitana.

No município de Piraquara, como no restante do país, a Educação Infantil apresentou, por muito tempo, um caráter assistencial. Na década de 1980, segundo Evelise Arco-verde,

Em termos de Paraná, a maior parte das pré-escolas das Redes Municipais está com os mesmos problemas da rede Estadual, apresentando algumas poucas pré-escolas em estabelecimentos municipais, os demais, fruto dos programas e projetos nacionais de desenvolvimento nesta área. As prefeituras municipais apresentam ainda dificuldade de pessoal especializado, em educação pré-escolar, não tendo com isto uma estrutura pedagógica adequada para a elaboração de préescola (ARCO-VERDE, 1985, p. 50).

A origem do atendimento pré-escolar em Piraquara está associada à Legião Brasileira de Assistência (LBA). No dia 10 de janeiro de 1949, no centro da cidade, foi inaugurado o Posto de Puericultura Francisco Leal, pertencente à LBA, que funcionou como posto de saúde. Nos fundos do prédio foi construída uma sala de madeira, na qual foram ministrados cursos de tricô e crochê para gestantes. Entretanto, o atendimento de crianças em espaço público apenas aconteceu na década de 1970.

Em 1975, foi desativada a sala de cursos, transformando-a em creche para atender crianças em idade pré-escolar. Após um ano de experiência, foi criada a creche da LBA dentro do posto de saúde, começando a atender uma média de 35 crianças carentes do município, permanecendo assim até 1991, com caráter marcadamente assistencialista.

Em 03 de junho de 1992, foi municipalizada a creche da LBA. Promoveu-se por meio de um ato administrativo, a cessão provisória e gratuita do imóvel de propriedade da LBA para a Prefeitura Municipal de Piraquara. Assim sendo, a referida creche da LBA passou a denominar-se Creche Pública Municipal Pingo de Gente, passando a atender 45 crianças na faixa etária de 02 a 06 anos e 11 meses de idade.

Entre as décadas de 1970 e 1980, as poucas instituições de Educação Infantil existentes eram mantidas pela LBA, através de programas federais nos quais a pré-escola era vista como solução dos problemas e fracassos ocorridos nas primeiras séries.

Entre os anos 1993 e 1994 houve a extinção da Legião Brasileira de Assistência no Município, sendo criada a Associação de Proteção à Maternidade e Infância (APMI) que exercia a função de prestar assistência social a sete instituições existentes. A partir de 1993, a Educação Infantil de Piraquara passou a ser orientada pelo Projeto Araucária, permanecendo oficialmente até 2004.

A APMI cessou suas atividades em 31 de dezembro de 2000, pois a partir de janeiro de 2001, a Educação Infantil passou a fazer parte da Secretaria de Educação, 
quando as instituições passaram à denominação de Centros de Educação Infantil. Tal medida estava de acordo com o dispositivo legal da Lei de Diretrizes e Bases da Educação 9394/96. Em 2001, iniciou-se um debate sob a coordenação da Secretaria de Educação com o objetivo de elaboração de uma nova proposta pedagógica. Em 2004, foi aprovada e implantada uma nova proposta pedagógica para a Educação Infantil. Nesse sentido, nossa pretensão analítica é evidenciar que a Educação Infantil em Piraquara organizou-se a partir da década de 1990, na tentativa de aproximar-se dos debates e das pesquisas produzidos na área da infância, pois por meio do Projeto Araucária e da Proposta Pedagógica da Secretaria da Educação buscou romper com uma educação assistencialista e promover um projeto educativo articulado a função social de cuidar e educar.

\section{Projeto Araucária: primeira proposta pedagógica da Educação Infantil}

A história da Educação Infantil tem dois marcos pedagógicos, a saber: Projeto Araucária (1993) e Proposta Pedagógica da Secretaria da Educação (2004). O Projeto Araucária Centro de Apoio à Educação Pré-Escolar foi um programa de extensão que a Universidade Federal do Paraná desenvolveu, tendo início em 1985, com o apoio da fundação Bernard Van Leer, da Holanda. Esse projeto surgiu com o objetivo de efetivar um espaço de Educação Infantil voltado para o desenvolvimento da criança e para a ampliação de seus conhecimentos, sendo esse documento uma alternativa de organização de creches e pré-escolas públicas.

Em sua primeira fase (julho de 1985 a dezembro de 1988), o Projeto Araucária atuou em parceria com o Serviço Social da Indústria - SESI e as Prefeituras Municipais de Curitiba e de Rio Branco do Sul (pertencente a grande Curitiba), dando atendimento a aproximadamente de 2.000 crianças. Nessa fase, as ações se direcionaram a implantação de uma Proposta Pedagógica para o trabalho com crianças de 04 a 06 anos, em escolas municipais e espaços alternativos existentes na comunidade e cedidos pelas instituições participantes.

Em 1988, após uma avaliação do projeto indicou que a formação de recursos humanos como condição essencial à garantia de qualidade do atendimento pedagógico oferecido às crianças. Consequentemente houve a necessidade de um redimensionamento das linhas de atuação do Projeto. O primeiro redimensionamento aconteceu entre janeiro de 1989 e dezembro de 1992. O segundo ocorreu a partir de 1993, no qual se integrou o Município de Piraquara. A partir de então, o Projeto Araucária transformou-se num Centro de Apoio ao Pré-Escolar desenvolvendo as seguintes ações: 1) Curso de aperfeiçoamento para diferentes categorias de profissionais que atuam com Educação Infantil (técnicos, professores, coordenadores, diretores, atendentes, cozinheiras e auxiliares); 2) Elaboração e implantação de Proposta Pedagógica para o atendimento à criança de 0 a 6 anos; 3) Produção de material didático-pedagógico; 4) Realização de pesquisas.

Os convênios com a LBA e a Prefeitura Municipal de Curitiba e dezessete municípios da região metropolitana da capital paranaense buscavam criar as condições para garantir a efetivação dessas ações em creches e pré-escolas.

Ao analisar a proposta do Projeto Araucária, percebemos um manual de orientação de atividades, tendo uma fundamentação teórica explicativa das razões, bem como a respeito dos encaminhamentos metodológicos a serem tomados. Já no início do documento consta a afirmação de que "as sugestões para a organização das atividades de rotina, pedagógicas e sobre organização dos ambientes aparecem intercaladas com comentários mais teóricos". (1993, p.04) 
A proposta apresentada contou com a participação da professora Sonia Kramer. Tal proposta foi implantada nas creches de Curitiba, sob a responsabilidade da Secretaria Municipal da Criança e nas creches dos municípios da região metropolitana, a cargo do Projeto Araucária. O trabalho de psicomotricidade relacional desenvolvido nas creches de Curitiba não foi estendido às creches da região metropolitana, pois, de acordo com o documento, elas não apresentavam condições estruturais adequadas. Outro aspecto que também difere a capital em relação à região metropolitana, refere-se à elaboração de material pedagógico de apoio para atendentes infantis, uma vez que as especificidades regionais determinavam as diversidades das atividades.

Para entendermos as políticas públicas voltadas para a infância no período em que vigorava o Projeto Araucária, vamos analisar primeiramente como eram entendidas as creches e pré-escolas.

Na década de 1990, muitos espaços alternativos de atendimento à criança de 0 a 6 anos surgem em todo Brasil, mas com dificuldade de suprir a demanda existente.

Segundo Sanches,

A ampliação de atendimento direto à criança pelo Estado não supre a demanda, surgindo em várias regiões atendimentos alternativos, como mães-crecheiras, lares vicinais, creches domiciliares, com atendimento mais barato e sem garantia de qualidade (2003, p.69).

Em Piraquara, por meio da Secretaria de Ação Social em parceria com a LBA que atendia em âmbito nacional, começou a ser repensada a educação e o cuidado com a criança, mesmo tendo espaços alternativos como casas adaptadas, na maioria delas sem as mínimas condições de atendimento. Nesse sentido, buscou-se por meio do Projeto Araucária um novo direcionamento e a possibilidade de um fazer pedagógico mais sistematizado, contando com duas coordenadoras pedagógicas que visitavam as instituições do município e auxiliavam as educadoras.

A educação começava a fazer parte do cotidiano infantil (sistematicamente), pelo menos para as crianças que tinham a garantia de estar em um espaço chamado creche ou pré-escola, pois havia a exigência de apresentar no ato da matrícula documentos que comprovassem renda e local de trabalho dos pais, o que caracteriza uma herança da educação como assistência, pois apenas alguns tinham o direito a acessar a Educação Infantil.

Do ponto de vista pedagógico, o Projeto Araucária veio para nortear o trabalho, trazendo fundamentação teórica e sugestões de atividades, tendo como referencial teórico Vygotsky e Piaget, pois até então as educadoras trabalhavam com as crianças usando atividades elaboradas por elas próprias, sem uma tendência pedagógica específica e sistematizada.

De acordo com Sanches, "historicamente, a creche apresenta características de assistência e recreação, precariedade de material e de formação dos profissionais. Quanto à educação, é espontaneísta, autoritária ou inexistente" (2003, p.43).

Ao analisar o Projeto Araucária, percebemos que ele é dirigido às educadoras de creche, pois afirma que "neste texto, buscamos apresentar algumas ideias que nos ajudam a pensar a proposta pedagógica para as crianças de nossas creches" (1993, p. 04). As educadoras de creche a que se refere o projeto são, para a pré-escola, professoras com formação mínima em magistério, e para a creche, as babás, estas tinham por objetivo, garantir lugar seguro e limpo para que as crianças pudessem passar o dia. Esse profissional deveria limpar, cuidar alimentar e evitar riscos de quedas, controlando certo número de crianças. Para essas educadoras, o Projeto Araucária trazia o passo a passo das atividades, 
como se fosse um manual. Podemos utilizar o seguinte trecho do projeto para sustentar essa assertiva: "procurar, sempre que possível, falar coisas interessantes com as crianças, e ouvir o que elas têm para contar (sobre a vida, suas roupas, cenas observadas, desenhos etc.) valorizando suas colocações e suas histórias". (1993, p.29). Podemos concluir que este trecho da proposta nos remete claramente a concepção da Escola Nova, tendo o aluno como o centro do processo, existindo uma preocupação muito grande com a natureza psicológica da criança.

Por intermédio do Projeto Araucária, as professoras e educadoras tiveram a oportunidade de receber formação continuada na mesma intensidade, pois uma vez ao mês elas se dirigiam à Universidade Federal do Paraná para receber orientações e explicações do que não tinham entendido no Projeto e formularem atividades e confecção de material de apoio.

As profissionais que atuam na Educação Infantil tinham um estigma de cuidadoras e não de educadoras. A história da Educação Infantil evidencia que em muitas instituições bastava ser mulher, ter experiência com crianças, particularmente com os próprios filhos, ter paciência, capacidade de expressar afeto e responsabilidade para exercer o papel de professora nos espaços de Educação Infantil.

O cuidado e a educação da criança de 0 a 6 anos seriam responsabilidades da família. No entanto, como as crianças estão indo cada vez mais cedo para as instituições infantis, o cuidado e a formação mais geral da criança são feitos pela educadora.

Segundo Silva,

Somente conseguiremos constituir uma política efetiva de formação de profissionais para a Educação Infantil, tanto para a habilitação profissional quanto no que se refere à formação continuada, se as agencias formadoras se dispuserem a, efetivamente, dialogarem com as experiências dos sujeitos dessa formação. A relação educativa entre adultos e crianças está estabelecida nas práticas dos grupos como práticas culturais e é preciso considerá-la para que possamos dialogar entre si (2002, p.210).

Outro aspecto a ser mencionado na análise das políticas públicas é a construção da proposta pedagógica. Kramer, no Prefácio do Projeto Araucária, afirma que a proposta não deve ser entendida como um documento absoluto e acabado. E observa que

Há certas propostas, porém, que acabam aprisionando a ação prática, pois estão cheias de receitas ou normas, esta que você vai ler, ao contrário [...] procura abrir espaço para o potencial criador das crianças e dos adultos que com elas, trabalham [...] (1993, s.p.).

O novo contexto educacional requeria a organização de uma Educação Infantil conformada por propostas curriculares mais flexíveis e abertas, nas quais o educador pudesse contribuir diretamente, participando da sua construção ou adaptando o currículo a sua turma.

O Projeto Araucária ressalta que:

Os cantinhos podem ser organizados por estantes baixas, com caixotes vazados ou com as próprias cadeiras e mesinhas das salas.

$\mathrm{O}$ adulto pode orientar a formação dos cantinhos, agrupando materiais afins, fazendo, por exemplo, o canto da casinha, dos jogos, da fantasia, dos fantoches, da bandinha, dos livros etc. É importante que os cantinhos 
passem por um contínuo processo de renovação, sendo enriquecidos com novos materiais sempre que houver oportunidade. Esta implantação dos cantinhos pode ser feita de forma gradativa e, para enriquecê-lo enquanto espaços diferenciados na sala podemos fixar ganchos nas paredes e teto, passando barbantes que servirão como sustentação para fazer tendas, cabanas ou paredes de pano (1993, p. 19).

Há também um espaço destinado às explicações sobre as rotinas.

A rotina da creche é feita de uma sequencia de várias atividades, momentos cotidianos de interação das crianças com os adultos e entre si. Estas rotinas bem exploradas possuem alto valor educativo. Elas podem ser ao mesmo tempo referenciais de segurança para as crianças e momentos de conversar, de brincar, de explorar. Momentos valiosos de relacionamento, de troca, de experiências, de incentivo ao desenvolvimento, de valorização da espontaneidade de cada criança. [...] algumas sugestões para explorar os momentos específicos da rotina. Entrada e saída das crianças, [...] são momentos importantes para o contato e o diálogo entre funcionários das creches e os pais das crianças. [...] ao chegar na sala, é importante que a criança tenha uma acolhida afetuosa e que a sala esteja preparada para recebê-la, com jogos e brinquedos à sua disposição. [...] a saída, que pode se tornar um momento de espera ansiosa, pode ser mais interessante e menos angustiante se o adulto planejar atividades. [...]

O banho [...] brincadeiras com água, com o próprio corpo, com objetos que flutuam; momento de sentir o toque carinhoso do adulto, de estabelecer verdadeiros diálogos. Momentos cotidianos, acima de tudo [...]

Troca de fraldas e banheiro também ao trocar as fraldas podemos conversar, ouvir, tocar o corpo, buscar estreitar os laços com cada bebê e enriquecer a qualidade dos diálogos.

Com as crianças do maternal I, inicia-se o processo de aprendizagem do [controle de esfíncteres], que permitirá a liberação do uso de fraldas. [...] as crianças podem ter várias chances de ir ao pinico ou ao vaso sanitário: na chegada, depois das refeições, no meio da manhã, etc. [...].

Sono até aproximadamente os 4 anos [maternal II], a maioria das crianças sente necessidade de dormir após o almoço, embora existam diferenças individuais importantes, que procuramos respeitar. Cada criança pode ter seu próprio colchonete, mesmo no berçário, onde talvez apenas os bebês menores precisem de berços. [...] As crianças que quiserem ficar acordadas podem desenvolver atividades mais calmas. [...]

Banho de sol, para as crianças menores, o banho de sol pode ser diário, respeitando sempre os limites horários recomendados [...] A criança pode estar com pouca ou nenhuma roupa, livre para movimentar-se à vontade. [...] Com a evolução das crianças, aumenta a importância de que sempre que possível, elas possam desenvolver atividades ao ar livre [...].

Hábitos de higiene é preciso que a criança tenha várias oportunidades para desenvolver hábitos de higiene como lavar as mãos, escovar os dentes, pentear os cabelos, etc.

A partir do maternal I, as crianças começam a realizar estas atividades sozinhas, ou com menos ajuda do adulto a cada vez. Este é um aspecto importante na evolução da autonomia das crianças e vale também para vestir-se e para outras atividades. [...] As atividades ligadas à higiene 
também podem ser momentos importantes de contato corporal, de evolução do conhecimento do corpo, de uso da linguagem e de aprendizagem, momentos que podem ser aproveitados pelo adulto.

Alimentação, como nas outras atividades de rotina, podemos considerar a alimentação fundamentalmente em seu aspecto educativo e relacional uma vez que esteja garantida a qualidade, a adequação e a limpeza dos alimentos oferecidos às crianças.

Quanto mais nova for a criança, mais importante será, dentro do conjunto de suas relações sociais, a hora de comer. Por isso, as prioridades são a busca da adaptação dos adultos ao ritmo de cada criança, a calma e o carinho [...] (1993, p.7 a 12).

É importante salientar que as atividades de rotina apresentadas têm ênfase no cuidado e na educação da criança, cumprindo o que mais tarde veio a ser chamada de funções da Educação Infantil.

No Projeto Araucária, o adulto é mencionado como mediador do conhecimento ao propiciar o desenvolvimento das crianças por meio de situações diversas, nas quais as crianças vão adquirindo autonomia. Nessa direção, o documento afirma que "quando a criança se relaciona com adultos que se adaptam bem a ela, tende a se sentir confiante e segura, e logo vai querer explorar tudo em volta de si” (1993, p.13).

O Projeto Araucária defende que:

O papel do adulto pode ser fundamental no processo de evolução do jogo simbólico e de outras formas de linguagem, não para impor os temas e os gestos às crianças, mas agindo no sentido de propiciar às crianças a possibilidade de ampliar sua experiência pessoal, ajudando-as, se necessário, a concentrar-se em temas de seu interesse, oferecendo os mais diversos materiais, ensinando a usá-los e valorizando as atividades expressivas de cada criança (1993, p.42).

Percebemos a presença das ideias de Vygotsky quando são mencionados os termos jogo simbólico e experiência pessoal.

A proposta sustenta, ainda, que as experiências já vividas são de suma importância. Nesse aspecto,

Gostaríamos de deixar claro que o texto reflete uma etapa dentro do percurso da Secretaria Municipal da Criança e do Projeto Araucária e que não existe nenhuma pretensão de esgotar o assunto. Pelo contrário, esta fundamentação teórica e as sugestões concretas estão sendo colocadas para serem discutidas, completadas, questionadas e enriquecidas em função de experiências, das condições da realidade concreta e das leituras de cada um (1993, p. 04).

As políticas públicas de atendimento à criança, principalmente na década de 1990, buscavam através de discussões capitaneadas pelo GT Educação da Criança de 0 a 6 anos e pela Coordenação Geral de Educação Infantil (COEDI) do MEC, estabelecer algumas direções teóricas e políticas para a educação da criança pequena. Nesse sentido, o Projeto Araucária é uma expressão das discussões dos especialistas da Educação Infantil, pois Sonia Kramer fazia parte do GT7 e integrou a equipe da COEDI coordenada por Ana Barreto no período de 1994 a 1997.

No prefácio do Projeto Araucária, há uma síntese do contexto das discussões a respeito da criança de 0 a 6 : 
Vivemos hoje, no Brasil, um momento especialmente fértil no que diz respeito à criação de alternativas públicas de trabalho com crianças de $0 \mathrm{a}$ 6 anos. As lutas de trabalhadores, de profissionais das mais diversas origens e da população organizada em diferentes movimentos sociais particularmente os de mulheres- ecoaram na Constituição de 1988 que, pela primeira vez na nossa história, assegura o direito das crianças a creches e pré-escolas e afirma o dever do Estado de provê-las. Os inúmeros debates que se desencadearam a partir daí, tanto em torno das Constituições Estaduais quanto das Leis Organizadas dos Municípios aprofundaram a consciência de que democratizar a Educação Infantil é tarefa fundamental, porque a educação - em todos os níveis - é um direito social das crianças. Neste cenário, assistimos, nos últimos anos, a iniciativas de muitas prefeituras que têm procurado garantir, na prática, a concretização desse direito (1993, s.p).

As discussões a respeito da democratização da Educação Infantil visam constituir o campo de produção de conhecimento sobre a educação da criança pequena, assim como pressionar o poder público a organizar políticas públicas efetivas a essa etapa da educação básica. O tratamento político dado à Educação Infantil foi, historicamente, de caráter mais assistencial do que educacional. A proposta do Projeto Araucária é concebida como uma estratégia de organização de uma pedagogia para a Educação Infantil. Portanto, as discussões que se iniciaram através das universidades e pessoas ligadas ao ensino infantil buscavam alternativas para a efetivação de políticas públicas para a infância, mas como bem sabemos não depende somente da sociedade civil, mas também de iniciativas governamentais.

A Educação Infantil ficou a cargo dos municípios para sua implantação e manutenção, no entanto, pouco é investido na educação das crianças de 0 a 6 anos. De acordo com os gestores da Educação de Piraquara,

[...] o município se depara, ainda, com as diversas situações que precisam ser analisadas e efetivadas pelo poder público [...] a falta de estrutura física nas instituições existentes conforme deliberação 003/99 [Normatização da Educação Infantil do Paraná]; financiamento não específico para a Educação Infantil [...] (2004, p.16).

No que diz respeito ao método de ensino-aprendizagem adotado pelo Projeto Araucária percebemos uma mescla de tendências pedagógicas (tradicional, tecnicista e escolanovista), embora o projeto afirme que sua concepção é sócio-histórica.

A este respeito os autores desse documento afirmam:

Nós optamos por uma fundamentação teórica em que a ênfase recai sobre o papel das interações sociais no desenvolvimento dos indivíduos. $\mathrm{Na}$ medida do possível, recorremos às ideias de Vygotsky e a outros trabalhos em que as interações sociais são consideradas essenciais para a compreensão do desenvolvimento infantil (1993, p.04).

Podemos citar algumas questões que dizem respeito ao método, justificando sua tendência pedagógica: "os adultos podem buscar organizar os espaços de forma a ampliar ao máximo as opções de atividades das crianças, dentro de um referencial de segurança, de incentivo à autonomia e à cooperação e de regras básicas [...]" (1993, p.15). Em outra 
passagem afirma-se que "a criança começa a exploração do meio sempre recorrendo ao adulto como fonte dos referenciais [...]" (1993, p.14).

É possível identificar a presença do construtivismo de Piaget, no qual o biológico e o psicológico são determinantes para as mudanças de estágios. A este respeito o documento postula que:

O bebê pode retirar um grande prazer destas situações de exploração, em que vai descobrindo o mundo e seus próprios poderes. Em 1926, Piaget descrevia da seguinte maneira suas experiências de observação de bebês que começam a explorar o mundo e a si mesmos [...] (1993, p.13).

Piaget é utilizado em vários momentos do documento como referencial, principalmente, quando são postas sugestões de atividades com os bebês e crianças até três anos. Em referência a Piaget o documento menciona a questão da afetividade: "estes contatos emocionais, que se baseiam, sobretudo na sensibilidade recíproca, na afetividade, no olhar, podem se transformar em verdadeiros diálogos, tônico - afetivo" (1993, p.05).

A concepção sócio-histórica está presente nas atividades de linguagem, pois Vygotsky é uma referência fundamental.

Aos poucos, por meio de um processo de assimilação que possui uma longa história e que se desenvolve em função da interação da criança com os outros, ela começa a ensaiar suas primeiras palavras, que nascem daqueles sons da linguagem que a criança assimila da fala do adulto quando ouve (1993, p.22).

Quando o projeto menciona o jogo infantil, menciona novamente Vygotsky. Através do faz de conta a criança vivencia o mundo adulto, realizando situações que não seriam possíveis de acordo com sua idade, por exemplo, dirigir um ônibus, um carro, um avião. O Projeto Araucária sustenta que "o jogo infantil como meio de expressão e como estratégia para a compreensão do mundo, considerando-o seriamente como uma fonte privilegiada de desenvolvimento das crianças" (1993, p.37).

Analisando as atividades propostas pelo Projeto Araucária verificamos que foi sugerido o trabalho com jogos e brincadeiras; percebemos ainda que as atividades propostas são de vivências cotidianas das crianças, como, por exemplo, jogos, brincadeiras com sombra, brincadeira de escutar sons, olhar nuvens, fazer experiências com diferentes elementos (areia, água, grama, etc.), observar bichos e plantas, conversar sobre elas.

No nosso entendimento, o Projeto Araucária foi uma experiência inovadora no contexto em que ele foi utilizado, tanto do ponto de vista teórico como prático, pois até aquele momento não existia uma proposta sistematizada que visasse orientar o fazer pedagógico da Educação Infantil no Município de Piraquara.

Em síntese, verificamos que muitos elementos importantes não apareceram no Projeto Araucária, entre os quais destacamos a ausência de dados das particularidades de cada município, o número de crianças não atendidas, o planejamento de construção de novos espaços educativos, as regiões com maior índice demográfico de pré-escolar, etc. Portanto, essa proposta foi encaminhada sem um estudo de caso específico. Se nos reportarmos a 1993, é possível afirmar que a Educação Infantil, sendo de responsabilidade da Secretaria de Ação Social, poderia assumir um caráter assistencial. Entretanto, o Projeto Araucária representou a tentativa de superação do assistencialismo, pois o caráter pedagógico buscava nortear o cotidiano da Educação Infantil na rede municipal. 


\section{Nova Proposta Curricular da Educação Infantil de Piraquara}

A Educação Infantil do município de Piraquara ficou sob a égide do Projeto Araucária entre 1993 e 2003, sendo substituído em 2004, quando surge uma nova Proposta Pedagógica para a Educação Infantil. No ano de 2001, a Secretaria Municipal de Educação assumiu a responsabilidade da Educação Infantil. As creches passaram a denominar-se Centros Municipais de Educação Infantil - CMEIS - adequando-se à nomenclatura estabelecida pela legislação nacional e passando a enfatizar um caráter educacional em consonância com as discussões da área de pesquisa da Educação Infantil, particularmente com a produção intelectual do Grupo de Trabalho Educação da criança de 0 a 6 anos da ANPED.

A partir do segundo semestre de 2001, começa o processo de construção de uma Proposta Pedagógica para os CMEIS, após convênio firmado com a Universidade Federal do Paraná para assessoria de elaboração, implantação e formação de professores. Diante da impossibilidade de envolver todos os professores da rede municipal, num primeiro momento, uma vez que os estudos realizaram-se durante o período das aulas, a solução encontrada foi a de reunir todas as diretoras dos CMEIS e iniciar o processo de reflexão e estruturação da nova proposta.

Os estudos foram desencadeados a partir do levantamento de questões teóricopráticas sobre o fazer pedagógico nos Centros Municipais de Educação Infantil e se desenvolveram por meio de leituras e discussões a respeito de temas relevantes para a elaboração da Proposta Pedagógica. As leituras, reflexões e discussões realizadas pelo grupo de estudos suscitaram muitas dúvidas, conflitos e negociações, possibilitando a constatação de contradições na prática docente e da necessidade de buscar mais esclarecimentos e fundamentação teórico-metodológica para a prática pedagógica na Educação Infantil.

Em março de 2002, as reflexões e discussões foram retomadas pelo grupo de estudo que, naquele momento, contava com a participação de uma nova Coordenação Pedagógica para a Educação Infantil na Secretaria de Educação e com assessoras pedagógicas no interior dos Centros de Educação Infantil.

Desse processo resultou, no primeiro semestre de 2002, a sistematização de textos básicos que apontavam, em caráter inicial, algumas direções para a Educação Infantil que se realizava nos centros municipais, tais como a tendência pedagógica a ser seguida, tendo a criança como sujeito de direito.

A partir do segundo semestre de 2002, grupos de estudos das áreas do conhecimento organizaram-se para discutir e propor encaminhamentos metodológicos para o trabalho com as crianças atendidas na rede municipal. Em 2003, continuou a elaboração e sistematização da Proposta curricular, retomando pendências do ano anterior. Em 2004 a Proposta Curricular foi implantada em todos os Centros Municipais de Educação Infantil, tendo como mediador no interior dos centros o coordenador pedagógico.

A elaboração da Proposta Curricular aconteceu após um amplo de debate entre os pesquisadores brasileiros da Educação Infantil, pois esta já estava inserida como nível do ensino básico, desde a lei 9394/96. Nessa lei, no artigo 62, temos o seguinte:

A formação de docentes para atuar na educação básica far-se-á em nível superior, em curso de licenciatura, de graduação plena em universidade e institutos superiores de educação, admitida a formação mínima para o exercício do magistério na Educação Infantil e nas quatro séries do ensino fundamental, a oferecida em nível médio, na modalidade normal. 
Formosinho:

O professor da Educação Infantil é diferente dos demais professores, como observa

Há, assim, na educação da infância uma interligação profunda entre educação e cuidados, entre função pedagógica e função de cuidados e custódia, o que alarga naturalmente o papel da educadora por comparação com o dos professores de outros níveis educativos (2002, p.137).

Como podemos perceber as funções da Educação Infantil são de educar e cuidar concomitantemente. Segundo a proposta curricular,

As exigências do momento atual vêm definindo para a Educação Infantil a função de educar e cuidar das crianças. Educação e cuidados passam a ser entendidos como aspectos indissociáveis da educação da criança de zero a seis anos de idade (2004, p.09).

Com a nova LDB, a educação básica envolve a Educação Infantil. Nesse sentido, a sua função divide-se em duas, uma voltada para o desenvolvimento infantil; outra, para o desenvolvimento de aprendizagens específicas, cabendo ao professor garantir essas peculiaridades. Cabia à mantenedora garantir e estabelecer programas de formação continuada em serviço. No que diz respeito a esse aspecto, a proposta afirma que: "[...] é ofertada tanto pela Secretaria Municipal de Educação quanto pelo CMEI em hora atividade" (2004, p.12). O documento sustenta que os Centros de Educação Infantil poderiam estabelecer momentos de formação, entretanto, a Secretaria de Educação definia que os temas relevantes seriam:

A atual função da Educação Infantil; Avaliação; Aprendizagem e Desenvolvimento; Oficinas com sugestões de encaminhamentos nas áreas do conhecimento para o trabalho dos professores; História da infância; Concepção de educação assumida pela SMED; A importância e finalidade do planejamento de ensino, e outros (2004, p.12).

Esta passagem evidencia que a Secretaria mantém o controle sobre os programas de formação, portanto, as experiências docentes foram relativizadas. A esse respeito, conforme Kramer, no processo de organização de formação em serviço:

[...] a maioria das iniciativas de formação trabalha com a idéia de que é preciso ou mesmo possível jogar fora a experiência passada e começar tudo de novo. Como se nós, professores, pudéssemos ser colocados em ponto morto, alavancados, a cada vez que descobrisse um novo método, uma nova proposta ou uma nova teoria $(1999$, p.157).

A elaboração da Proposta Curricular da Educação Infantil faz parte de uma política nacional, sendo uma ação necessária para a garantia da qualidade no ensino infantil. A Proposta foi produzida por oito consultores da Universidade Federal do Paraná (dois específicos sobre Educação Infantil e seis, um para cada área do conhecimento), pela equipe pedagógica da Secretaria Municipal de Educação de Piraquara, por coordenadores pedagógicos e diretoras dos Centros Municipais de Educação Infantil. Por meio de leituras de textos e discussões coletivas foi elaborada a Proposta Curricular da Educação Infantil.

$\mathrm{Na}$ apresentação da proposta, sustenta-se que esse documento põe-se como a única diretriz do fazer pedagógico. Nessa direção, a Secretária de Educação afirma que "temos certeza de que esta proposta será efetivada e implementada, na medida em que todos os 
profissionais da Educação Infantil envolvam-se na continuidade de sua elaboração, tornando-se autores do fazer pedagógico" (2004, s.p.).

Já na introdução, a proposta é descrita como um documento que pode ser questionado e revisto, pois postula:

Coerente com a intenção de envolver todos os professores no ato de construção desta proposta, o grupo não teve, em momento algum, a pretensão de elaborar um documento fechado. Ao contrário, o texto, que chega agora às mãos dos profissionais da Educação Infantil, representa o primeiro passo de um processo que se desenvolve, se amplia e que, muitas vezes, se caracteriza por avanços e retrocessos e que não finalizam um processo, mas se renovam cotidianamente, na medida em que se renovam o tempo e as relações sociais $(2004$, p.11).

A proposta se dirige aos professores, embora faça tabula rasa do Projeto Araucária que, por longo período, norteou as atividades pedagógicas da Educação Infantil. O documento ressalta que,

Pela primeira vez, no município, professores da rede municipal de ensino reúnem-se com o objetivo de pensar e propor caminhos para a Educação Infantil. Esses profissionais, assim como todos os que estão ousando, hoje, participar ativamente da elaboração de propostas pedagógicas nas instituições em que atuam, carecem de exercícios e amadurecimento pelo fato de terem ficado, por muito tempo, alijados da possibilidade de pensarem, proporem, realizarem, de serem os autores, e não meros executores da ação pedagógica (2004, p.11).

Ao mesmo tempo em que a proposta apresenta-se como única possibilidade para mudar a Educação Infantil, abre espaço para ser questionada. Nos termos do documento, "não podemos perder de vista que esta proposta, que é fruto de um trabalho apenas inicial, precisa ser continuamente (re) elaborada, sempre a partir de discussões coletivas [...]" (2004, p. 12).

A proposta compreende a infância e a Educação Infantil dentro do materialismo histórico dialético, pois a criança é concebida como um sujeito histórico, portanto, é necessário considerar a sua condição de "ser social, a sua historicidade e as formas de que a sociedade dispõe e cria para educá-la" (2004, p.12).

Os eixos da proposta são divididos em natureza e especificidade da Educação Infantil, a infância e a Educação Infantil, a função da Educação Infantil e a formação humana, a aprendizagem e o desenvolvimento, bem como os textos de cada área do conhecimento.

A concepção de criança que aparece na proposta é de um ser social, histórico e que faz parte da sociedade. O documento afirma que objetiva-se "evidenciar a criança como ser histórico e social, ou seja, que se constitui numa determinada sociedade, cuja infância se realiza a partir das relações existentes" (2004, p.19). A educação é compreendida como um dos meios de transformação social.

Os referenciais da proposta foram trabalhados de forma coletiva, uma vez que coordenadores pedagógicos e diretores participavam das discussões, os professores tinham acesso ao debate no horário destinado à preparação das atividades, no próprio centro de Educação Infantil.

O documento apresenta de maneira breve um olhar histórico a respeito da infância ao afirmar que, 
A idéia de infância transforma-se ao longo da história, na medida em que transforma o modo de organização da vida dos homens... Uma nova visão de infância vem se configurando na sociedade contemporânea, marcada por inúmeras transformações decorrentes da revolução nas tecnologias de informação, pela interdependência global das economias mundiais e pelo acirramento da competição entre elas, pela integração global dos mercados financeiros, pela incorporação maciça das mulheres na força de trabalho remunerada, pela individualização e diversificação cada vez maior das relações de trabalho, de bem estar social, pelo novo sistema de comunicação que fala cada vez mais uma língua universal e digital [...] (2004, p.19).

Ao debater sobre a necessidade de democratização da Educação Infantil, o documento utiliza os termos "vontade" e "esperança" para indicar o desejo dos gestores em universalizar este nível de ensino. A rigor, salienta a proposta, "este esforço junta-se ao movimento nacional de construção da Educação Infantil que tem por base a busca de qualidade e a democratização do ensino para as crianças de 0 a 6 anos de idade" (2004, s. p.). Entrementes, o documento não faz referência aos recursos necessários para garantir uma pedagogia de qualidade na Educação Infantil.

Há um diagnóstico referente à Educação Infantil, particularmente ao número de crianças atendidas, à formação dos profissionais, à criação de novas instituições, à ampliação e aquisição de materiais pedagógicos. As situações de precariedade são apresentadas na proposta:

O município se depara, ainda, com as diversas situações que precisam ser analisadas e efetivadas pelo poder público em conjunto com a comunidade, como por exemplo, a falta de oferta de vagas às crianças de 0 a 6 anos, em especial, as de 0 a 1 ano e 11 meses, já que o município não dispõe de berçário; falta de estrutura física nas instituições existentes conforme deliberação 003/99; financiamento não específico para a Educação Infantil; necessidade de rompimento com práticas escolarizantes; a falta de articulação com os demais segmentos da sociedade civil organizada [Conselho Tutelar, Saúde, Assistência social, entre outros]; adequação do número de crianças por docentes, condizentes com a legislação; falta de professores no quadro; entre outras situações (2004, p.16).

Embora o documento faça referência à inexistência de vagas para todas as crianças de 0 a 6 anos, não apresenta o número de crianças excluídas do ensino infantil. Ademais, não indica as regiões que têm maior demanda por novas vagas.

As áreas do conhecimento que compõem a proposta são: língua portuguesa, matemática, ciências, geografia, artes, educação física e história, o que evidencia forte aproximação com a Diretriz Municipal do Ensino Fundamental, de 2002, pois se tratam das mesmas áreas.

No item que trata da aprendizagem e do desenvolvimento da criança, o documento explica às educadoras/professoras como acontece o aprendizado e o desenvolvimento, afirmando que,

O processo de desenvolvimento - que é essencialmente social - ocorre de forma integrada aos aspectos físicos, cultural e psicológico. Ele possibilita que a criança constitua-se como indivíduo com personalidade 
própria e como parte integrante de um grupo, a partir das experiências concretas que realiza em seu meio (2004, p.26).

A concepção adotada, segundo a proposta, é o materialismo histórico dialético. O documento afirma:

\footnotetext{
Esta proposta fundamenta-se no materialismo histórico dialético, estando voltada para a transformação social em favor da classe trabalhadora, e deve ser compreendida como um referencial teórico-prático, objetivando a democratização do ensino infantil e da socialização do saber produzido historicamente pela humanidade (2004, p.12.).
}

As áreas do conhecimento não são articuladas, cada uma tem sua especificidade. Os conteúdos são pertinentes aos aspectos sociais e culturais, sendo conhecimentos universais.

A este respeito o documento salienta que:

A busca de um ensino coerente na Educação Infantil fundamenta-se na compreensão da necessidade da criança apropriar-se e construir uma visão sobre o mundo, sobre si, desenvolvendo suas potencialidades para compreender e interferir na realidade (2004, p.25).

O documento afirma, em diversos momentos, que essa proposta é um marco histórico no processo de constituição da Educação Infantil e sustenta que o materialismo histórico e dialético é o único que dá sustentação para organizar um projeto educativo com caráter transformador.

O documento postula a superação do velho pelo novo. Nesses termos, essa proposta se coloca na cena política, ou seja, no espaço pedagógico como mecanismo capaz de superar todas as mazelas existentes. Muitas coisas importantes foram esquecidas e abandonadas, inovações foram criadas e recriadas. Ao construir uma proposta deve-se compreender e analisar minuciosamente a "antiga" para não reinventar a roda, como afirma Kuhlmann Junior. No processo de disputa do novo contra o velho os protagonistas usam de diferentes estratégias discursivas para deslegitimar o que existia, o que demonstra que no plano das políticas públicas o embate não se dá apenas no plano técnico, mas fundamentalmente, no plano político. Ou seja, é preciso deslegitimar o velho e legitimar o novo. No afã de deslegitimar o Projeto Araucária, o novo documento sustenta que a antiga proposta tinha "como referencial teórico os pressupostos do construtivismo" (2004, p.10). É preciso ressaltar que, ao contrário do que afirma o documento de 2004, o Projeto Araucária se definia fundamentado na teoria histórico-crítica.

\section{Considerações finais}

O objetivo deste artigo foi discutir as duas propostas pedagógicas para a Educação Infantil implantadas no Município de Piraquara, buscando evidenciar a hipótese que o Projeto Araucária (1993) e a Proposta Pedagógica da Secretaria da Educação (2004) procuravam romper com o caráter assistencialista e promover uma pedagogia da Educação Infantil. Nesse aspecto, analisamos as acepções de infância e de Educação Infantil que emergiram das duas propostas pedagógicas. A par dessas acepções problematizamos as questões referentes aos métodos de ensino-aprendizagem, a formação dos professores.

A primeira experiência sistemática de uma proposta pedagógica para a Educação Infantil em Piraquara foi o Projeto Araucária. Esse projeto consistiu em um programa de extensão que a Universidade Federal do Paraná desenvolveu, tendo início em 1985, cujo 
objetivo foi estabelecer diretrizes pedagógicas para a educação da criança pequena. Em sua primeira fase (julho de 1985 a dezembro de 1988), o Projeto Araucária atuou em parceria com o Serviço Social da Indústria - SESI e as Prefeituras Municipais de Curitiba e de Rio Branco do Sul, dando atendimento a aproximadamente 2.000 crianças. No ano de 1988, os grupos envolvidos realizaram a avaliação da proposta e concluíram que a mesma deveria sofrer algumas alterações, particularmente no que diz respeito à necessidade de elaborar um programa de formação de recursos humanos a fim de garantir a qualidade do atendimento pedagógico oferecido às crianças. Em 1993, Piraquara estabeleceu parceria com os responsáveis pelo Projeto Araucária, constituindo-se em um avanço para a realidade da Educação Infantil, pois pela primeira vez havia uma orientação teóricometodológica, portanto, uma proposta pedagógica orientada por Sonia Kramer, pertencente ao Grupo de Trabalho Educação da criança de 0 a 6 anos da ANPED. Tal observação indica que a experiência vivenciada pelos municípios da grande Curitiba procurava aproximar-se das discussões mais recentes promovidas no campo intelectual brasileiro. É em razão disso que defendemos a hipótese de que o Projeto Araucária representou a primeira proposta pedagógica para a Educação Infantil em Piraquara.

No final da última década do século $\mathrm{XX}$, os municípios brasileiros precisaram adaptar-se à LDB 9394/96, particularmente no aspecto que determinava a obrigatoriedade de inclusão da Educação Infantil no sistema básico de Educação. Em Piraquara, a Educação Infantil passou à responsabilidade da Secretaria de Educação a partir de 01 de janeiro de 2001. Em consonância com esse ato, os gestores iniciaram um processo de construção da nova proposta pedagógica que deveriam nortear o trabalho docente nos Centros de Educação Infantil. No plano lega, a mudança consistia na inclusão da Educação Infantil no sistema de ensino, uma vez que pela legislação vigente (Lei de Diretrizes e Bases da Educação Nacional 9394/96), a Educação Infantil tornar-se-ia a primeira etapa da educação básica e passaria a ser de responsabilidade da Secretaria Municipal de Educação. No plano pedagógico, deveria ser organizada uma proposta que privilegiasse o caráter educativo da criança pequena. Nesse sentido, entre 2001 e 2004 houve um processo contínuo de formação e discussão que culminou na formalização de uma nova proposta pedagógica para a Educação Infantil.

Ao longo deste artigo foi possível destacar que em Piraquara, no período de 1993 e 2004, as políticas públicas expressaram a vontade de romper com o caráter apenas assistencialista e buscaram promover a defesa de uma pedagogia para a Educação Infantil. A proposta de 2004 postulava uma representação enviesada do projeto pedagógico elaborado em 1993, pois sustentava que até então a Educação Infantil do município enfatizou apenas o cuidado da criança. Os documentos por nós analisados evidenciaram que, mesmo sob os cuidados da Secretaria de Ação Social, a educação da criança pequena expressava os elementos do cuidar e do educar. Nesse sentido, o discurso sobre o "novo" continha elementos que já estavam no "velho". Dito de outra forma é possível sustentar que as políticas públicas para a Educação Infantil em Piraquara, estabelecidas em dois momentos diferentes, não podem ser concebidas como proposições antagônicas, pois os documentos evidenciam que é equivocada a assertiva de que apenas recentemente as creches e pré-escolas tornaram-se instituições educativas.

Portanto, esta análise evidencia que as duas propostas pedagógicas, implantadas em 1993 e 2004, estabeleceram uma forte preocupação com o enfoque pedagógico, pois reivindicavam a necessidade de professores com formação acadêmica, a existência de coordenadores pedagógicos e programas de formação continuada como elementos essenciais para garantir uma pedagogia de qualidade na educação da criança pequena, o que indica uma relação de aproximação com o debate intelectual promovido pelo GT7 da 
ANPED, assim como a pretensão de atender ao ordenamento jurídico da Constituição Federal de 1988 e da Lei de Diretrizes e Bases da Educação Nacional 9394/96.

\section{Referências}

ARCO-VERDE, Y. F. S. Estudo sobre a prática pedagógica desenvolvida nas préescolas das redes de ensino de Curitiba. Curitiba (Dissertação de Mestrado em Educação), Universidade Federal do Paraná, 293f. 1985.

BRASIL, Lei de Diretrizes e Bases da Educação Nacional. Lei n 9394 de 20 de dezembro de 1996, Brasília.

FORMOSINHO, J. O. O desenvolvimento das educadoras de infância: entre os saberes e os afectos, entre a sala e o mundo. In: MACHADO, M. L. A. (Org.). Encontros e desencontros em Educação Infantil. São Paulo: Cortez, 2002, p. .

KRAMER, S. Propostas pedagógicas ou curriculares: subsídios para uma leitura crítica. In: MOREIRA, A. F. B. (Org.). Currículo políticas e práticas. São Paulo: Papirus, 1999.

KULHMANN M. J. Infância e Educação Infantil: uma abordagem histórica. Porto Alegre: Mediações, 2001.

PIRAQUARA, Diretrizes Curriculares Municipais. Ensino fundamental: $1^{\mathrm{a}}$ a $4^{\mathrm{a}}$ séries. Piraqura, 2002.

PIRAQUARA, Proposta Curricular da Educação Infantil. Piraquara: Skalagraf, 2004.

UNIVERSIDADE FEDERAL DO PARANÁ, Projeto Araucária. Curitiba, 1993.

SANCHES, E. C. Creche: realidade e ambigüidades. Petrópolis: Vozes: 2004.

SILVA, I. O. A profissionalização do professor da Educação Infantil: questões sobre a formação dos profissionais que estão em serviço. In: MACHADO, M. L. A. (Org.). Encontros e desencontros em Educação Infantil. São Paulo: Cortez, 2002.

Notas

\footnotetext{
${ }^{1}$ Professora Assistente da Universidade Estadual do Paraná - Campus Paranaguá. Doutoranda em Educação pela Pontifícia Universidade Católica do Paraná, na linha de pesquisa em História e Políticas da Educação. danielle.marafon@fafipar.br
} 